\title{
Making pre-school children wear masks is bad public health
}

\author{
Dr Robert C Hughes1, Dr Sunil S Bhopal1,2, Prof Mark Tomlinson 3,4
}

1 Department of Population Health, London School of Hygiene and Tropical Medicine
2 Faculty of Medical Sciences, University of Newcastle
3 Department of Global Health, Stellenbosch University
4 School of Nursing and Midwifery, Queens University Belfast

Children are not small adults. This is a critical point that many pediatricians and other child health professionals get bored of saying, yet it does seem to need repeating. While children have the lowest risk from COVID-19 directly, they risk suffering the indirect impacts of policy decisions, many of which appear to have been made with next to no explicit consideration of their interests. Public health interventions should not only be about infectious disease control, they should consider a broad set of outcomes. In addition, they ought to consider vulnerability, including that in early childhood - a time when young children's brains are developing rapidly and are most susceptible to adversity. We believe that mandating masking of pre-school children is not in line with public health principles, and needs to be urgently re-considered.

Last week, President Biden's Chief Medical Adviser Dr Fauci promoted the new US CDC Childcare Guidance, which states that "Masks should be worn indoors by all individuals (ages 2 and older) who are not fully vaccinated(1). We feel that the CDC and Dr Fauci have, by focusing exclusively on SARS-CoV-2 transmission, got this wrong, and that this guidance is not good public health when the limited potential benefits of this policy are considered alongside the potential harms.

The importance of early childhood for the rest of a person's life is now well understood; what happens in those early moments really matters, and changing the beginning has the potential to change the whole story - including learning, earning and happiness(2). In addition, the centrality of responsive caregiving and interaction - such as that between peers and with caregivers in the home and childcare settings - is increasingly well appreciated, affecting language and social-emotional development and $I Q(3)$.

This interaction and engagement is much more than an optional 'nice to have' that can be deferred for a few years whilst the pandemic is controlled; the window of ensuring optimal early childhood development is short(4). During this period moment by moment engagement, caregiver responsiveness, and learning of social cues (including by reading the faces of caregivers and others) are crucial for early socio-emotional development, for learning the 'give and take' of peer interaction and crucially for developing a 'theory of mind'(5). It would be considered grossly unethical to attempt to assess the impact of covering the faces of young children and their caregivers on early childhood development. The potential for harm here is clear, especially when you consider the long hours that many children spend in childcare settings(6). 
These risks to early childhood development are especially concerning when balanced against the potential benefits that mandating young children to wear masks might plausibly bring (even before considering likely levels of 'compliance' with mask wearing amongst toddlers). There are three potential benefits here that seem worthy of consideration; reduced risk of Covid-19 to the child and their peers, reduced risks to their caregivers, and wider benefits for SARS-CoV-2 epidemic control.

Considering the first of these, it is increasingly clear that SARS-CoV-2 - thankfully represents an extremely low mortality risk to children(7). In addition, current experimental estimates of the risks of prolonged symptoms also suggest that these are least common amongst young children(8) and likely similar to risks they face from other viruses.

Regarding the risk that unmasked toddlers represent to adults caring for them, in the US and other high-income countries, childcare staff have now been, or are being, offered highly effective vaccines which significantly reduce their risk of staff acquiring SARS-CoV-2, especially from young paucisymptomatic or asymptomatic young children.

Finally, while the wellbeing of the young children and their caregivers who are the subject of this policy ought to be central to decision making, it is worth noting that the contribution of pre-school settings to wider epidemic dynamics appears to be limited and less than that of secondary schools or universities(9). This may be due to younger children having mostly asymptomatic infection, with associated lower secondary attack rates and onward transmission.

As the consensus builds that SARS-CoV-2 will become an endemic pathogen it is crucial that we focus our effort on interventions that are as harm-free and benefit-rich as possible. This may well include mask wearing amongst healthy adults becoming a collective cultural activity where it makes sense (for example in crowded places, especially indoors and where ventilation is poor). But we do not feel that extension of this intervention to pre-school children is to be advised, let alone mandated. It is noteworthy that the World Health Organization explicitly advises against masking young children under the age of five(10).

In summary, the benefits of masking pre-school children are unclear but are probably too small to make a major difference to individuals risks from SARS-CoV-2 or epidemic control (even before considering variable likely compliance amongst toddlers). In contrast, the harms of this policy are likely to be damaging, potentially considerably so. Given this, and the influence that the CDC and Dr Fauci have both in the US and globally, we believe an urgent re-consideration of this policy is needed.

Declaration of interests: The authors declare that they have no known competing financial interests or personal relationships that could have appeared to influence the work reported in this paper.

Funding: none received for this work

\section{References:}


1. CDC, CDC. Guidance for Operating Early Care and Education/Child Care Programs [Internet]. Centers for Disease Control and Prevention. 2021 [cited 2021 Jul 22]. Available from: https://www.cdc.gov/coronavirus/2019-ncov/community/schoolschildcare/child-care-guidance.html

2. Gertler P, Heckman J, Pinto R, Zanolini A, Vermeersch C, Walker S, et al. Labor market returns to an early childhood stimulation intervention in Jamaica. Science. 2014 May 30;344(6187):998-1001.

3. Shonkoff JP, Garner AS, The Committee on Psychosocial Aspects of Child and Family Health C on EC, Siegel BS, Dobbins MI, Earls MF, et al. The Lifelong Effects of Early Childhood Adversity and Toxic Stress. Pediatrics. 2012 Jan 1;129(1):e232-46.

4. Doyle O, Harmon CP, Heckman JJ, Tremblay RE. Investing in early human development: Timing and economic efficiency. Economics \& Human Biology. 2009 Mar 1;7(1):1-6.

5. Siegel DJ. The Developing Mind: How Relationships and the Brain Interact to Shape who We are. Guilford Press; 2012. 530 p.

6. Mills MC, Praeg P, Tsang F, Begall K, Derbyshire J, Kohle L, et al. Use of childcare in the EU Member States and progress towards the Barcelona targets. 2014 [cited 2021 Jul 22]; Available from: https://ora.ox.ac.uk/objects/uuid:7898acd0-b47f-449f-8cad3d0bcf4b0142

7. Smith C, Odd D, Harwood R, Ward J, Linney M, Clark M, et al. Deaths in Children and Young People in England following SARS-CoV-2 infection during the first pandemic year: a national study using linked mandatory child death reporting data. medRxiv. 2021 Jul 8;2021.07.07.21259779.

8. Prevalence of ongoing symptoms following coronavirus (COVID-19) infection in the UK Office for National Statistics [Internet]. [cited 2021 Jul 22]. Available from: https://www.ons.gov.uk/peoplepopulationandcommunity/healthandsocialcare/conditionsa nddiseases/datasets/alldatarelatingtoprevalenceofongoingsymptomsfollowingcoronaviru scovid19infectionintheuk

9. Lachassinne E, Pontual L de, Caseris M, Lorrot M, Guilluy C, Naud A, et al. SARS-CoV2 transmission among children and staff in daycare centres during a nationwide lockdown in France: a cross-sectional, multicentre, seroprevalence study. The Lancet Child \& Adolescent Health. 2021 Apr 1;5(4):256-64.

10. WHO. Coronavirus disease (COVID-19): Children and masks [Internet]. [cited $2021 \mathrm{Jul}$ 22]. Available from: https://www.who.int/news-room/q-a-detail/q-a-children-and-masksrelated-to-covid-19 